\title{
Innovation Through Universal Design in Agile UX Software Development Teams A Collaborative Case Study of an Under Graduate AR Tourist Guide Project
}

\author{
Enda FINN ${ }^{a, 1}$ and Jere KUUSINEN ${ }^{b}$ \\ ${ }^{\text {a }}$ Lecturer, DkIT \\ b Senior Lecturer SATAKUNTA UAS
}

\begin{abstract}
The study has the objective of designing AR tourist guide mobile app within an academic teaching framework facilitating collaborative (e.g. external commercial partners), cooperative (i.e. external academic experts) and user-centred design (UCD). [1]The tourist guide app, VisitAR, is a digitized tour application that portrays information in the form of landmarks and information windows. VisitAR provides a seamless walking experience in real-time by using your location, and triggering pop up information windows while you walk at Carlingford Ireland. The application testing was completed by using several usability evaluation methods i.e. technical field testing, living lab testing including speaking thoughts out loud, usability focus group testing and usability analysis As a result, by teaching UD within an experiential, living lab, a more realistic design context is provided, addressing realistic UX and SD, allowing deployment of potentially commercially viable solutions, which address the needs of a more diverse range of end users. As part of this case study, both qualitative and quantitative data related to UX, usability and SD from each stage of development was evaluated.
\end{abstract}

Keywords. Universal Design, Service Design, Agile UX, Augmented Reality

\section{Introduction}

This case study considers the design of an AR Tourist Guide mobile app, as well as a similar and related, immersive 360 video, web application, both of which were being developed and delivered as part of an under-graduate team project, within an academic teaching framework facilitating collaborative (e.g. external commercial partners), cooperative (i.e. external academic experts) and user-centred design (UCD). [1]

The Team Project facilitates and supports final year students in teams [15] of four to six participants operating a full software development life cycle. This operates on an Agile UX project management framework that employs industry standard, professional toolsets, platforms and development techniques. An academic project mentoring and assessment panel of discipline specialists supports students, backed up by external academic research specialists, as well as industry and commercial partners. Perhaps most

\footnotetext{
${ }^{1}$ Corresponding Author. Dundalk Institute of Technology.Dublin Road, Dundalk Co. Louth A91 K584.

E-mail: Enda.Finn@dkit.ie
} 
importantly, external collaborators representing potential customers, special and demanding user groups as well as application domain experts from a wide variety of realworld domains (tourism being one such example) also engage directly in the design, development and testing of each release phase of the Agile UX process. Careful supervision and coordination ensure that the academic aspects of the learning experience take precedence over any potential commercial considerations or demands although these are valuable and important.

\section{Theoretical background}

Universal Design (UD) concepts and principles are considered and applied within the Agile UX development environment and can often involve users directly as co-designers where this is feasible and appropriate. The broader UD philosophy also opens up consideration of wider cohorts of user groups, particularly special and demand user needs, as well as the potential for better or enhanced user support in a different contexts and usage environments [3]. It is important to note that an academic ethics committee, both at the concept proposal stage and later at "live" (or if necessary simulated) user trial stages, considers all projects. This is particularly important where projects address the needs of special user groups, vulnerable users or users within specific and restricted age categories. Appropriate measures required within the design of the application and the operation of the project to protect and secure user data, ensure user anonymity and safeguard user rights are carefully applied. These challenges provide realistic "hands on" learning opportunities for students and further emphasise a "universal" and "empathetic" design philosophy and approach.

Another core concept, which is emphasised from the outset of each project, is innovation, both from a technical perspective and a commercial point of view. Both the desire for and the demand to deliver technical innovation, even to a limited degree, makes sense from an academic point of view especially as it pushes students to engage with and learn about new and more advanced interaction techniques, devices and development platform. Furthermore, from a commercial point of view the demand for some degree of innovation, particularly in relation to products and services is self-evident and pretty much a must have feature. However, there is another aspect of innovation that relates to providing accommodation of or potentially even breakthrough for demanding end user needs. It is one of the core tenants of UD that we deliberately emphasise design for the extreme (or at margins) user rather than just the normal (or average) users. This focus helps to promote innovative solutions, by definition and by necessity, which can be very beneficial to all users and help facilitate more effective and support features in different usage contexts. [4]

Furthermore, the Team Project module, the Agile UX development model and the broader academic delivery and assessment methods deployed have been reviewed by the external accreditation body [5] and by the CEUD as part of their respective legislative and national policy and remits, in order to promote and enhance the teaching of UD at third level [14]. Indeed, the ongoing development and improvement in embedding of UD within these programmes is an example of best practice. It is both the opinion and the experience of authors of this paper that proactive championing of UD's inclusion at the core of modern Computing undergraduate degree programmes is an absolute necessity. UD provides a realistic, viable and workable exemplary that helps students and academic staff to better understand, address and alleviate usability issues in general, and more 
specialist aspects of universal usability and accessibility for demanding and special needs user groups and cohorts in particular. [7] This case study goes further along this already established approach to consider Service Design (SD) aspects as well.

Simply "dropping" UD concepts and content into one or two specialist modules is not sufficient. Yes, it may tick the "usability" or "accessibility" box, as being "covered on this programme of study", but this alone will not adequately facilitate the application of a UD process and its associated design principles, nor the timely evaluation of the impact of such on actual user experience. In addition, the effective mapping of UDs "four Ds", i.e. Define, Design, Develop and Deliver into an Agile UX process model takes considerable thought and ongoing effort. This mapping is however achievable and can and does provide a realistic and workable platform for applying UD at the undergraduate coalface. [8]

Both of the projects considered in this case study have each been progressed iteratively through these four phases, with a continuous emphasis on user review, feedback and ultimately, actual user performance being measured against specific UD design principles. As with most of the projects undertaken over the past number of years within this process, there is also a of risk of not achieving some or even all of the requirements identified. This is due mainly to the exploratory and innovative nature of designs proposed, the degree of technical complexity often involved and also the at times limited experience and capability of the undergraduate student developers. These risks do not normally adversely affect the quality the learning experience gained, nor the level of academic achievement attained. Indeed, as with most real-world design innovation, it is only when risk of (a degree of) failure is apparent that there exists the potential for real breakthrough. Providing multiple iterations (and hence assessment checkpoints) helps to significantly mitigate the overall negative impact on design and development. Such setbacks (as have been apparent in the case of the specific projects in this case study) have proved to be almost inevitable.

Furthermore, it is worth remembering that the full integration of a UD process and design principles within IT is still a relatively new concept, particularly within an academic project setting. UD has only been an enforceable standard for around the last 10-15 years. There is currently an emerging interest in usability and accessibility generally and UD more specifically, driven largely by necessity given the introduction of the new EU directive on Web and Application accessibility. [9] This not only defines and applies a more demanding standard of design usability and accessibility for ICT products and services; it also demands that usability and accessibility levels can be demonstrated on an ongoing basis. This will force commercial, public sector and even academic organisations to address usability, accessibility, UX and UD in order to demonstrate compliance, as well as hopefully, demonstrably improving design and delivery of products and services for their users! With this background in mind, it has become much easier to justify the need for inclusion of and active engagement both with UD and more broadly SD within both academic and commercial training arenas.

But even aside from the emergence of the legislative enforcement and compliance models that make a strong or even an unavoidable case for UD inclusion, the "must do" case so to speak, there has been and continues to be, in the authors experience at least, a very compelling "should do" case for UD. This in our view relates especially and particularly to the fostering and enabling of innovation in design through UD inclusion. In particular, by deliberately embracing the more demanding requirements of special users or even extreme users, in more challenging usage environments and contexts, this provides, in our experience, a catalyst which empowers the "design thinking" of students, 
most especially when they can relate to and emphasise with particular and often quite challenging special user needs.

\section{The goals of this paper}

With this paper we provide a model for teaching Universal Design and Agile UX process in a collaborative framework. We also provide an application concept about seamless walking experience in real-time by using your location and triggering pop up information windows while you walk at Carlingford Ireland, which demonstrates the both the and the impact of UD and SD on Agile UX in a technologically innovative and challenging environment.

\section{Methods}

By teaching UD within an experiential, living lab, a more realistic design context is provided, addressing realistic UX and SD, allowing deployment of potentially commercially viable solutions, which address the needs of a more diverse range of end users. As part of this case study, both qualitative and quantitative data related to UX, usability and SD from each stage of development is considered.

The Agile development life cycle model employed within the Team Project module defines four distinct development release stages. Each Agile release stage is broken into development sprints of two weeks each. Firstly, there is the concept stage (three sprints to Release 1), then a pre-production stage (of between six and seven sprints depending, to Release 2) where core functionality is provided in a working prototype. This is followed by a production stage (of three to four sprints depending, to Release 3 ) which delivers the complete prototype (in terms of functionality and user requirements). The final stage is post-production (of two sprints, to Release 4). This postproduction prototype is intended to deliver a near "commercially viable" prototype which has undergone more extensive user testing and / or field trials in a (near fully) realistic fieldbased deployment (i.e. Living lab) that is then "launched" at an open, public project expo event.

As part of the academic assessment process, expert evaluation and appropriate user testing is undertaken at each of the four release stages of prototype development outlined above. This testing goes from very informal to semi-formal to highly structured and formal as each development stage progresses. It is conducted by student team members and supported by academic staff, in order to determine and validate specific requirements (Release 1) and then to ensure provision of appropriate functionality (Release 2), adequate usability and acceptable user experience (Release 3) and more optimized usability and user experience (Release 4). Students have therefore begun to address user needs and requirements from the very start, including idea brainstorming, concept generation and technology evaluation (Release 1). Concepts are rapidly prototyped, pitched and reviewed by the supervision panel and external collaborators acting as expert or user proxies or user champions. This is especially important for identifying particular special or demanding user needs.

It is important to remember that this specific case study had to integrate with and provide minimum disruption to the core Agile UX development plan and process, the academic assessment and the overall project management priorities. The methods 
outlined in the case study have been carefully constructed to provide additional support to already planned field trials (Release 2 and particularly Release 3 ) through expert observation of this "living lab". This is then followed by additional expert heuristic evaluation around UD principles in particular (Release 3 ) and finally through an external SD evaluation (focusing on Release 3 and especially Release 4 functionality and features) in order to assess the full-scale deployment potential for a commercially viable product.

\section{Evaluating the app on the field}

The student project at the core of this case study is VisitAR (see Figure 1), which is a tour guide, native mobile application. It is based around the picturesque medieval town of Carlingford. Carlingford, situated on the shores of Carlingford Lough, Ireland's most scenic fjord nestled between the Cooley Mountain in the south and the majestic Mountains of Mourne in the north, was originally founded by the Vikings and further developed and fortified (including the construction of an extensive Castle and town walls) by the Normans.

VisitAR has a target user age demographic of between 50-60-year-old tourists, both foreign and domestic, and is being developed and deployed in collaboration with local and regional tourist industry representatives.

The core feature of the application is to give users a live (location aware and position tracking) guided tour of Carlingford using their smartphone. The app helps them locate,

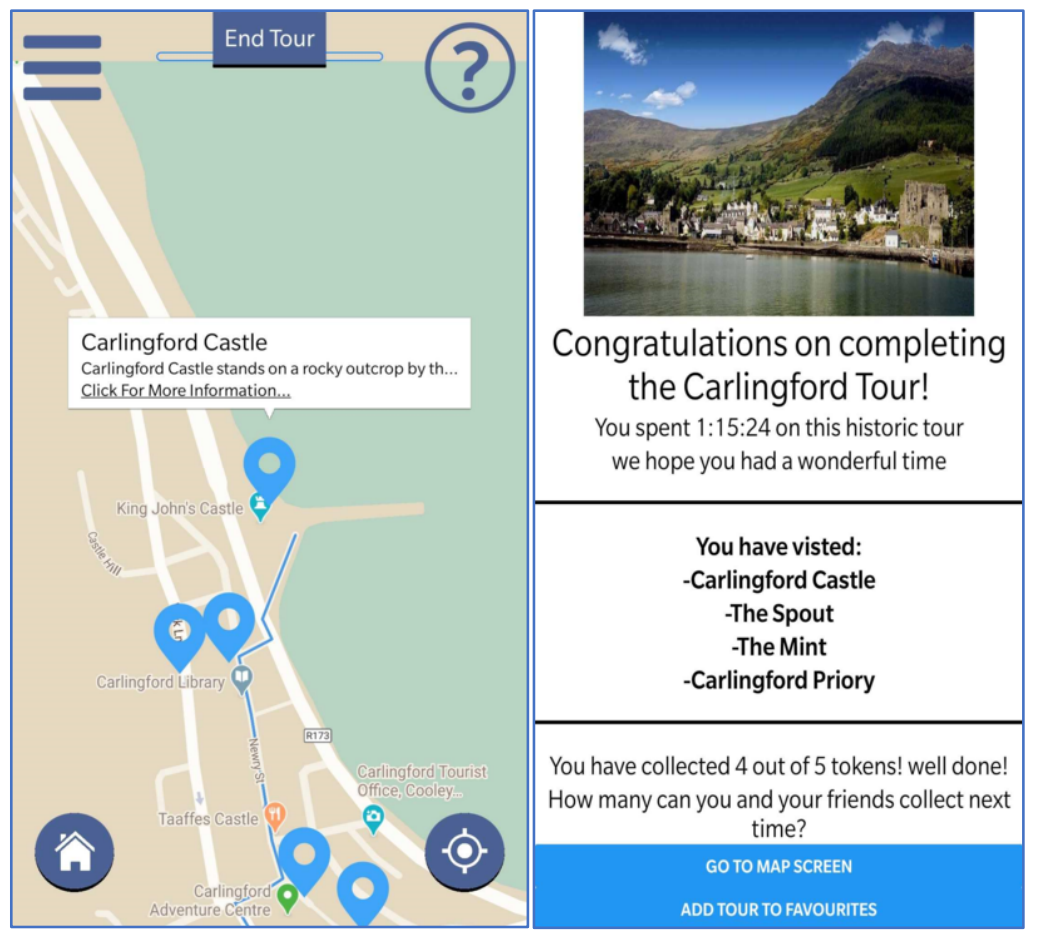

Figure 1. VisitAR (AR Tourist Guide mobile app) 
visit, and more interactively experience historical and heritage sites in the town, and to participate in a token collecting game, leading to rewards available for users from collaborating local businesses. The app incorporates multi-modal interaction (e.g. text to speech) as well as location and context sensitivity and at degree of visual and information augmentation. At the pre-production stage (Release 2) the app provides no advanced visual AR functionality as this proved to be very complex and difficult to integrate, being too unstable for field-based evaluation. [15]

The focus group testing included the selection of users for the field evaluation based on realistic user personas, with appropriate consideration and representation of potential special user needs within the target demographic age range (i.e. 50-60 years old) in particular. The real target group of application are active seniors or independent travellers like "cultural purists" who appreciate freedom and are hostile to pre-planning, preferring instead to follow their own instincts and interests, and may avoid well-known research sources [13]. As nowadays digitalisation has changed dramatically the behaviours of travellers during last couple decades making them more self-guided and more independent. Digital applications like VisitAR allow individuals to plan their travel on their own and without the guide.

Due to the COVID-19 pandemic restrictions we were able to complete only some parts of field tests limitedly. Firstly, the student team member (Murray) evaluated the application technically at Carlingford by giving multiple tasks to user group. The purpose of this technical field test is to manually test all of the application features that were present in the app by that date. Secondly, usability and UX were assessed using the Living Lab research concept. This session was focused merely on the look and feel of VisitAR and consisted of approximately 10 participants giving feedback on the user interface elements and the ease of use. The primary goal with the Living Lab was to obtain insight on the main usability flaws within the application, such as UI elements being too big or too small, cognitive overload, etc. The test consisted of a majority retrospective probing.

During the Living Lab users were allowed users were of course allowed to speak their thoughts aloud while they used the app. They were also asked to fill in a survey after the test. The session helped to find which key features are the most important and what they would like to see the app become - not to mention bringing usability flaws such as small text and ambiguity within the app to our attention. The session also aided team in making crucial development calls for the app for release two, such as adding distance between markers, making every landmark unique, and focusing on making navigation easier. Thirdly, based on results from the Living Lab a student team created a questionnaire and interview for next user group. This session also included recording for post assessment and haptic feedback. The participants were encouraged to speak up and call out errors found. The student team gained some valuable feedback on the features of the app, such as the poly-line for directions needing alterations, buttons being too large and text being too small, etc. In conclusions, the goal of all stages in final release is to eliminate at least $60 \%$ of all initial usability flaws [24].

\section{Conclusions}

The emphasis of real disruption and set-backs caused by COVID-19 pandemic and restrictions, the emphasize on real UD/SD and the application of Agile UX within collaborative process proved very resilient and managed to deliver a workable solution. 
Agile UX will facilitate UD and better support more quantitative evaluation of user data. By teaching UD collaboratively within an experiential, living lab environment this provides more realistic context. Developing innovative solutions successfully requires still more integration between UD process and IT. Based on our experience, developing successful digital innovations is a holistic process. Technological and economic aspects must be combined with the users' perspective iteratively, targeting incremental improvement of overall user experience.

\section{References}

[1] Collaborative Project module, B.Sc. (Hons) in Computing / Game Development, [courses.dkit.ie/ index.cfm/page/module/moduleId/55522] Accessed 20.2.2020

[2] Bachelor of Science (Honours) in Computing in Software Development, Programme ACS, [http://courses.dkit.ie/index.cfm/page/course/courseId/1090] Accessed 20.2.2020

[3] Centre for Excellence in Universal Design, What is Universal Design, [http://universaldesign.ie/Whatis-Universal-Design/] Accessed 20.2.2020

[4] Craddock, G., Gilligan, J., Finn, E., Kinsella, M., (2015). "Creating Champions of Inclusion Mainstreaming Universal Design into the Curriculum", Higher Education in Transformation Symposium, Dublin Castle 30th March to 1st April 2015, available online at http://www.highereducationintransformation.com/contentfiles/2015HEIT_Workshop_Book_of_Abstracts.pdf\#page=19 Accessed 20.2.2020

[5] [QQI, 2014] Quality and Qualifications Ireland, HE Award Standards, Policy for Determining Awards Standards, 2014 available online at https:/www.qqi.ie/Publications/Publications/ Policy\%20for\%20Determining\%20Award\%20Standards.pdf Accessed 24.2.2020

[6] Centre for Exellence in Universal Design, Awards and Education, [http://universaldesign.ie/Awards/] Accessed 20.2.2020

[7] "Embedding Universal Design at the core of a Computing Degree programme: key challenges faced and lessons learned", Education Across the Continuum: Innovating Through Universal Design Conference, Dublin Castle 12th \& 13th of November, available online at http://education.universaldesign.ie/Contents/Embedding-Universal-Design-at-the-core-of-a-ComputingDegree-programme-key-challenges-faced-and-lessons-learned.html Accessed 20.2.2020

[8] [Finn, E., and Coleman, G. 2018], "Integrating and delivering Universal Design in Agile UX software development teams", Workshop, Universal Design \& Higher Education in Transformation Congress , Dublin Castle 30th October to 2nd of November, Abstract available online at https://docs.wixstatic.com/ugd/c416fd_ac75eb0ba8a34508bd90078fb5e74fa4.pdf Accessed 20.2.2020

[9] [EU Web Accessibility, 2018] Implementation of the Web Accessibility Directive, Establishing a model accessibility statement and establishing a monitoring methodology, [https://ec.europa.eu/digital-singlemarket/en/news/publication-implementing-acts-under-web-accessibility-directive] Accessed 24.2.2020

[10] [Finn, E, 2015-b] "Mobile App Development for Well-Being Enhancement: Key Lessons from Specific User Experience." In: Satakunta University of Applied Sciences UAS MASTERS SYMPOSIUM III, "Full Life For All”, Andrew Sirkka (Eds.). pp 35, ISBN 978-951-633-161-7 (print), ISBN 978-951633-162-4 (pdf).

[11] [IGBL, 2016] Irish Symposium on Game Based Learning 2016, Trinity College Dublin (TCD), "Haven: a configurable simulation game designed to elicit an emotional response." Available on-line at [https://igblconference.wordpress.com/presenters/] Accessed 24.2.2020

[12] [EdTech, 2018] Using the Gamification of Augmented Procedures to Improve the Educational Experience, EdTech2018, May 31st and June 1st 2018, IT Carlow, available on-line at [http://programme.exordo.com/edtech2018/delegates/presentation/57/] Accessed 24.2.2020

[13] Amadeus company. TOMORROW'S, TRAVELLER. FUTURE TRAVELLER TRIBES 2030. [https://amadeus.com/documents/en/retail-travel-agencies/research-report/amadeus-future-travellertribes-2030-report.pdf] Referred 20.2.2020

[14] [Ref CEUD-c, 2020] Centre for Excellence in Universal Design, 7 Principles of UD, [http://universaldesign.ie/What-is-Universal-Design/The-7-Principles/] Accessed 20.2.2020 